\title{
Short Communication: Genotype by Environment Interaction Due to Heat Stress
}

\author{
J. Bohmanova, ${ }^{\star 1,2}$ I. Misztal, ${ }^{\star}$ S. Tsuruta, ${ }^{*}$ H. D. Norman, $†$ and T. J. Lawlorł \\ *Department of Animal and Dairy Science, University of Georgia, Athens 30602 \\ †Animal Improvement Programs Laboratory, Agricultural Research Service, USDA, Beltsville, MD 20705 \\ ‡Holstein Association USA Inc., Brattleboro, VT 05301
}

\section{ABSTRACT}

Heat stress was evaluated as a factor in differences between regional evaluations for milk yield in the United States. The national data set (NA) consisted of 56 million first-parity, test-day milk yields on 6 million Holsteins. The Northeastern subset (NE) included 12.5 million records on 1.3 million first-calved heifers from 8 states, and the Southeastern subset (SE) included 3.5 million records on 0.4 million heifers from 11 states. Climatic data were available from 202 public weather stations. Each herd was assigned to the nearest weather station. Average daily temperature-humidity index (meanTHI) $3 \mathrm{~d}$ before test date was used as an indicator of heat stress. Two test-day repeatability models were implemented. Effects included in both models were herd-test date, age at calving class, frequency of milking, days in milk $\times$ season class, additive genetic (regular breeding value) and permanent environmental effects. Additionally, the second model included random regressions on degrees of heat stress $(\mathrm{t}=\max [0$, meanTHI - 72]) for additive genetic (breeding value for heat tolerance) and permanent environmental effects. Both models were fitted with the national and regional data sets. Correlations involved estimated breeding values (EBV) from SE and NE for sires with $\geq 100$ and $\geq 300$ daughters in each region. When heat stress was ignored (first model) the correlations of regular EBV between $\mathrm{SE}$ and NE for sires with $\geq 100(\geq 300)$ daughters were $0.85(0.87)$. When heat stress was considered (second model), the correlation increased by up to 0.01 . The correlations of heat stress EBV between NE and SE for sires with $\geq 100(\geq 300, \geq 700)$ daughters were 0.58 $(0.72,0.81)$. Evaluations for heat tolerance were similar in cooler and hotter regions for high-reliability sires. Heat stress as modeled explains only a small amount

\footnotetext{
Received March 15, 2006.

Accepted October 23, 2007.

${ }^{1}$ Corresponding author: jbohmano@uoguelph.ca

${ }^{2}$ Current address: CGIL, Department of Animal and Poultry Science, University of Guelph, Guelph, Ontario, N1G 2W1 Canada.
}

of regional differences, partly because test-day records depict only snapshots of heat stress.

Key words: genotype $\times$ environment interaction, reaction norm, heat stress

Dairy farming in the United States is scattered over a wide range of climatic and topographic regions. Therefore, if significant genotype by environment interaction $(\mathbf{G} \times \mathbf{E})$ exists, then reranking of sires in different regions of the United States can be expected. The interaction can be modeled by different statistical models: 1) model with additional effect of $\mathrm{G} \times \mathrm{E} ; 2$ ) multitrait model defining records coming from different environments as different traits; and 3) model with genotype-specific random regression on environmental variables; that is, a reaction norm model, where phenotype is expressed as a function of environmental descriptors (e.g., herd production level, herd size, temperature, humidity, and geographic position). The last model allows for changes in the environment on a continuous scale.

Large $\mathrm{G} \times \mathrm{E}\left(\mathrm{r}_{\mathrm{g}}=0.88\right)$ have been reported between countries with different climatic and production systems, such as New Zealand and the United States (Weigel et al., 2001). However, most within-country studies did not detect significant interactions (Carabaño et al., 1990; Rekaya et al., 2003).

Zwald et al. (2003) investigated the effectiveness of 13 genetic, management, and climatic variables in international dairy sire evaluation as indicators of production environments. They found lower heritability in herds from cold climates $(0.26)$ than in herds from hot climates (0.39). The genetic correlation between those 2 groups was 0.66 . This may suggest that heat stress plays an important role in $\mathrm{G} \times \mathrm{E}$. In the study by Norman et al. (2005), correlations between national and regional evaluations for first-parity milk yield ranged between 0.96 (Northeast) and 0.88 (Southeast).

Ravagnolo and Misztal (2000) proposed a model that accounts for heat stress using test-day (TD) milk yield records and weather data from public weather stations. In their reaction-norm model, each animal has 2 genetic effects, a "regular" effect corresponding to performance 
Table 1. Summary statistics of national and regional data sets

\begin{tabular}{lccc}
\hline Item & National & Northeast & Southeast \\
\hline First parity test-day records (n) & $55,494,545$ & $12,505,982$ & $3,451,223$ \\
Heifers (n) & $5,797,297$ & $1,293,429$ & 357,130 \\
Average milk yield $(\mathrm{kg})$ & 29.1 & 28.3 & 27.4 \\
Variance of milk yield $\left(\mathrm{kg}^{2}\right)$ & 54.8 & 53.9 & 54.0 \\
Primiparous heifers per herd, average (n) & 21 & 16 & 25 \\
Sires (n) & 160,058 & 59,921 & 28,126 \\
\hline
\end{tabular}

in thermoneutral conditions and a "heat-stress" effect corresponding to the rate of decline of milk production in heat-stress conditions. The model was first applied to TD milk yields in Georgia and then Florida (Ravagnolo and Misztal, 2002). The correlation between the 2 genetic effects was negative, and the genetic variance due to heat stress was substantial at high temperaturehumidity indices. Bohmanova et al. (2005) applied a similar model to the US national data. Comparisons using official US PTA from February 2005 indicated that heat-tolerant sires were below average on fluid milk, above average on fertility and productive life, and average on Total Production Index (TPI). Sires used in the Southeast were below average for heat tolerance because of prevalence of fluid milk pricing in the region. Therefore, problems of heat stress in the Southeast are likely to increase over time.

The best way to prevent the deterioration of heat tolerance would be a routine evaluation that considers heat stress and subsequent selection for best performance under heat stress. If the effect of genotype by environment iteration is captured by the "heat stress" genetic effect, then the correlations between regions for "regular" evaluations should increase, compared with a model that ignores heat stress. However, this increase is likely to be influenced by quality of weather data and efficacy of cooling devices in different climatic regions.

The aim of this study was to estimate the increase in rank correlations between EBV of sires for milk yield from national and regional evaluations when heat stress is considered and to determine whether sires rank the same for heat tolerance in different regions.

The data were obtained from AIPL/USDA and included first-parity TD milk yields of Holsteins calved between 1993 and 2004. The National data set (NA) consisted of 55,494,545 TD records on 5,797,297 heifers. The Southeast and the Northeast were defined as in Norman et al. (2005). The Northeastern data set (NE) included 12,505,982 TD records from Connecticut, Massachusetts, Maine, New Hampshire, New Jersey, New York, Pennsylvania, and Rhode Island on 1,293,429 heifers. The Southeastern data set (SE) included 3,451,223 TD records from Arkansas, Alabama, Florida, Georgia, Louisisana, Mississippi, North Carolina,
Oklahoma, South Carolina, Tennessee, and Texas on 357,130 heifers. All TD records were required to be between 5 and 365 DIM. A more detailed description of the data is given in Table 1. As presented in Figure 1 , the majority of records in SE $(77 \%)$ originated from Texas (31\%), North Carolina (16\%), Georgia (12\%), Tennessee (11\%), and Florida (7\%). The majority of records in NE (85\%) originated from New York (44\%) and Pennsylvania (41\%), as shown in Figure 2.

Hourly meteorological data (temperature and relative humidity) were available from 202 public weather stations across the United States. Temperature humidity index (THI) was determined from temperature $\left({ }^{\circ} \mathrm{C}\right.$, temp) and relative humidity in percentage $(\%, \mathrm{rh})$ as follows (NRC, 1971):

$$
\begin{gathered}
\text { THI }=[1.8 \times \text { temp }+32] \\
-[0.55-0.0055 \times \text { rh })][1.8 \times \text { temp }-26] .
\end{gathered}
$$

Average daily THI was obtained by averaging hourly THI over $24 \mathrm{~h}$ and rounding to the nearest whole number. Average daily THI $3 \mathrm{~d}$ before (meanTHI) the test date was assigned to each TD record from the nearest weather station. The choice of the 3-d lag between weather and yield TD was based on results from a separate unpublished study (J. Bohmanova), in which it was shown that weather data $3 \mathrm{~d}$ before the test date explained more of the variability of milk yield than

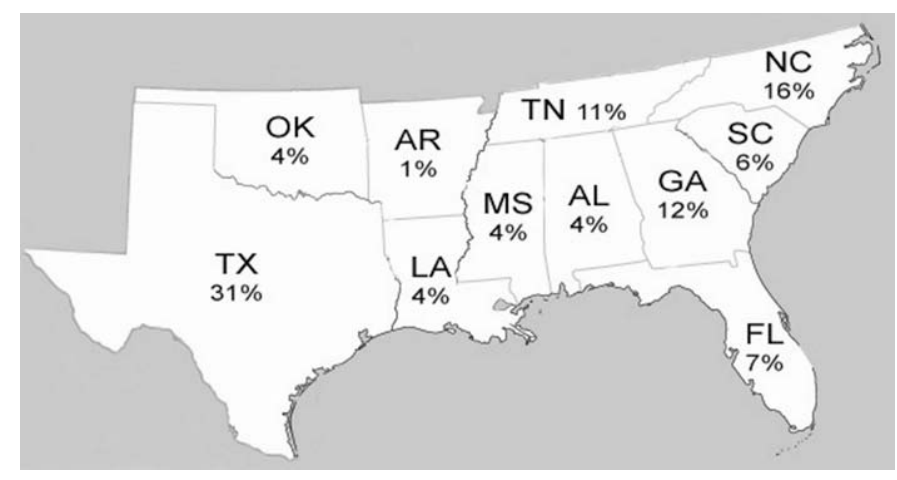

Figure 1. Proportional distribution of test-day records in the Southeastern data set by state. 


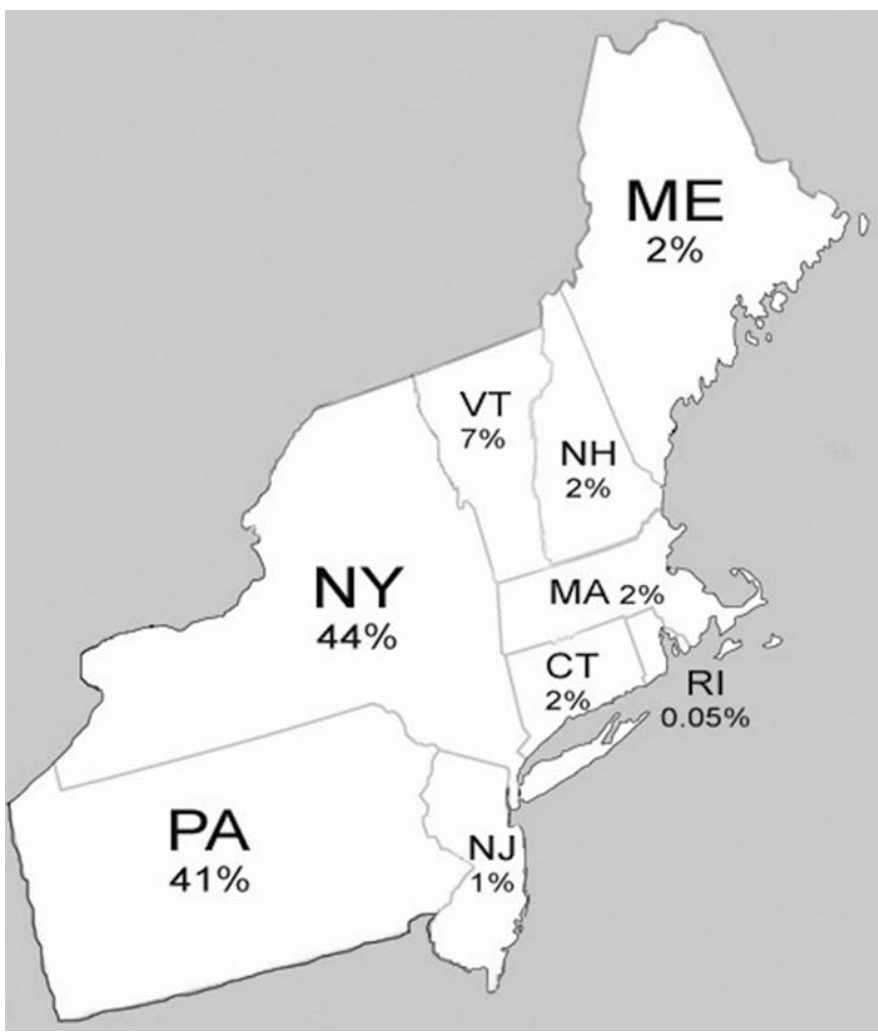

Figure 2. Proportional distribution of test-day records in the Northeast data set by state.

weather data 1 or $2 \mathrm{~d}$ before the TD or on the TD itself. The threshold of heat stress was set to a meanTHI of 72 for all herds. Level of heat stress on the farm depends on many factors, including the use and type of cooling devices. However, this information was not available.

Heat stress degree $(\mathbf{t})$ was used to estimate the decline of milk production caused by heat stress. Heat stress degree was defined as the number of units of mean THI above 72. Therefore,

$$
\begin{aligned}
& \text { if meanTHI } \leq 72 \text {, then } \mathrm{t}=0 \text { (no heat stress) } \\
& \text { else if meanTHI }>72 \text {, then } \mathrm{t}=\text { meanTHI }-72
\end{aligned}
$$

Sums of yearly heat-stress degrees were calculated for every public weather station and used as a description of thermal conditions in individual states. Florida, Louisiana, and Texas were the states with the highest heat-stress degrees per year in the United States, with 916,818 , and 761 heat-stress degrees per year, respectively (Table 2). Looking at regions, SE had, on average, 596 heat-stress degrees per year compared with 88 in NE. The national average was 239.

As shown in Figure 3, 10, 7, and 27\% of TD records were obtained on days with thermal stress (meanTHI
$>72$ ) in the NA, NE, and SE data sets. In SE, $14 \%$ of TD records were measured on moderate heat-stress days $(73 \leq$ meanTHI $\leq 76)$ and $13 \%$ on severe heatstress days (meanTHI $>76$ ).

Two repeatability animal models were used for national and regional genetic evaluations of TD milk yields.

The standard model was as follows:

$y_{i j k l m n r}=h t d_{i}+a g e_{j}+f r e q_{k}+\operatorname{dim}_{l m}+a_{0 n}+p_{0 r}+e_{i j k l m n r}$

where $h t d_{i}$ is the fixed effect of the $i$ th herd-test date, $a g e_{j}$ is the $j$ th age at calving class $(j=1$ to 8$)$, freq $_{k}$ is $k$ th frequency of milking ( $k=1$ to 4 ), $\operatorname{dim}_{l m}$ is the $l$ th DIM class $(l=1$ to 37$)$, with classes defined every 10 $\mathrm{d}$, nested within season $m$ ( $m=1$ to 4$), a_{0 n}$ is the regular additive genetic effect for animal $n, p_{0 r}$ is the regular permanent environmental effect for animal $r$, and $e_{i j k l m n r}$ is the residual. The variances of additive genetic effect, permanent environmental effect, and residual were $5.44,9.46$, and 15.74 , respectively.

The expanded model used the reaction-norm approach to account for $\mathrm{G} \times \mathrm{E}$, which expressed milk yield as a function of degrees of heat stress. The model was as follows:

$$
\begin{gathered}
y_{i j k l m n r}=h t d_{i}+a g e_{j}+\text { freq }_{k}+\operatorname{dim}_{l m}+a_{0 n}+a_{1 n} \times t+p_{0 r} \\
+p_{1 r} \times t+e_{i j k l m n r},
\end{gathered}
$$

where $a_{0 n}$ is the additive regular genetic effect independent of the level of heat stress, indicating the animal's ability to produce milk in thermoneutral conditions, $a_{1 n}$ is the additive genetic linear random regression coefficient of heat tolerance for animal $n$, describing the animal's environmental sensitivity to thermal stress, $p_{0 r}$ is the regular permanent environmental effect (the basic level), and $p_{1 r}$ is the permanent environmental random regression effect (slope) of heat tolerance for animal $r$.

The variance covariance structure was:

$$
\operatorname{var}\left[\begin{array}{c}
a_{0} \\
a_{1} \\
p_{0} \\
p_{1} \\
e
\end{array}\right]=\left[\begin{array}{ccccc}
A \sigma_{a}^{2} & A \sigma_{a \alpha} & 0 & 0 & 0 \\
A \sigma_{a \alpha} & A \sigma_{\alpha}^{2} & 0 & 0 & 0 \\
0 & 0 & I \sigma_{p}^{2} & I \sigma_{p \pi} & 0 \\
0 & 0 & I \sigma_{p \pi} & I \sigma_{\pi}^{2} & 0 \\
0 & 0 & 0 & 0 & I \sigma_{e}^{2}
\end{array}\right],
$$

where $\sigma_{a}^{2}=5.50, \sigma_{a \alpha}=-0.18, \sigma_{\alpha}^{2}=0.03, \sigma_{p}^{2}=9.56, \sigma_{p \pi}=$ $-0.24, \sigma_{\pi}^{2}=0.01$, and $\sigma_{e}^{2}=15.70$.

Breeding values were estimated by BLUPIODF90 (Tsuruta et al., 2001), a program that handles large 
Table 2. Number of weather stations per state, average (mean), minimal, maximal, and standard deviation (SD) of yearly heat-stress degrees per state

\begin{tabular}{|c|c|c|c|c|c|c|}
\hline \multirow[b]{2}{*}{ State } & \multirow{2}{*}{$\begin{array}{l}\text { Weather } \\
\text { stations } \\
\text { (n) }\end{array}$} & \multicolumn{4}{|c|}{ Heat-stress degrees per year } & \multirow[b]{2}{*}{ Region } \\
\hline & & Mean & Minimum & Maximum & SD & \\
\hline Alabama & 3 & 439 & 346 & 533 & 93 & Southeast \\
\hline Arkansas & 2 & 562 & 542 & 582 & 28 & Southeast \\
\hline Arizona & 2 & 701 & 480 & 922 & 312 & - \\
\hline California & 8 & 95 & 0 & 333 & 126 & - \\
\hline Colorado & 3 & 6 & 0 & 14 & 7 & - \\
\hline Connecticut & 2 & 96 & 79 & 113 & 24 & Northeast \\
\hline Delaware & 1 & 189 & 189 & 189 & - & - \\
\hline Florida & 8 & 916 & 637 & 1427 & 290 & Southeast \\
\hline Georgia & 6 & 452 & 320 & 616 & 112 & Southeast \\
\hline Iowa & 4 & 122 & 84 & 166 & 34 & - \\
\hline Idaho & 3 & 24 & 3 & 40 & 19 & - \\
\hline Illinois & 5 & 152 & 93 & 202 & 43 & - \\
\hline Indiana & 4 & 165 & 100 & 295 & 92 & - \\
\hline Kansas & 4 & 285 & 193 & 364 & 75 & - \\
\hline Kentucky & 5 & 216 & 113 & 331 & 101 & - \\
\hline Louisiana & 4 & 818 & 696 & 938 & 120 & Southeast \\
\hline Massachusetts & 2 & 60 & 30 & 91 & 43 & Northeast \\
\hline Maine & 3 & 81 & 9 & 212 & 114 & Northeast \\
\hline Michigan & 7 & 53 & 18 & 99 & 25 & - \\
\hline Minnesota & 5 & 37 & 9 & 83 & 30 & - \\
\hline Missouri & 4 & 289 & 233 & 375 & 63 & - \\
\hline Mississippi & 3 & 498 & 446 & 555 & 54 & Southeast \\
\hline Montana & 5 & 2 & 0 & 9 & 4 & - \\
\hline North Carolina & 5 & 265 & 27 & 501 & 172 & Southeast \\
\hline North Dakota & 3 & 32 & 18 & 44 & 13 & - \\
\hline Nebraska & 7 & 124 & 13 & 214 & 77 & - \\
\hline New Hampshire & 1 & 32 & 32 & 32 & - & Northeast \\
\hline New Jersey & 2 & 183 & 156 & 210 & 38 & Northeast \\
\hline New Mexico & 1 & 23 & 23 & 23 & - & - \\
\hline Nevada & 4 & 133 & 0 & 520 & 258 & - \\
\hline New York & 5 & 42 & 16 & 51 & 15 & Northeast \\
\hline Ohio & 7 & 89 & 45 & 137 & 32 & - \\
\hline Oklahoma & 2 & 492 & 434 & 551 & 83 & Southeast \\
\hline Oregon & 7 & 7 & 0 & 16 & 7 & - \\
\hline Pennsylvania & 7 & 111 & 46 & 247 & 73 & Northeast \\
\hline Rhode Island & 1 & 82 & 82 & 82 & - & Northeast \\
\hline South Carolina & 3 & 443 & 250 & 609 & 181 & Southeast \\
\hline South Dakota & 4 & 68 & 22 & 97 & 36 & - \\
\hline Tennessee & 5 & 313 & 64 & 575 & 186 & Southeast \\
\hline Texas & 12 & 761 & 214 & 1324 & 332 & Southeast \\
\hline Utah & 1 & 47 & 47 & 47 & - & - \\
\hline Virginia & 7 & 207 & 40 & 385 & 118 & - \\
\hline Washington & 5 & 5 & 0 & 16 & 7 & - \\
\hline Wisconsin & 5 & 71 & 43 & 105 & 25 & - \\
\hline West Virginia & 4 & 69 & 12 & 141 & 62 & - \\
\hline Wyoming & 4 & 2 & 0 & 5 & 2 & - \\
\hline
\end{tabular}

data sets using iteration on data technique with preconditioned conjugate gradient algorithm.

As shown in Table 3, 636 sires had $\geq 100$ daughters in both $\mathrm{NE}$ and $\mathrm{SE}$. Those sires had on average 6,171 , 1,413 , and 487 daughters in NA, NE, and SE, respectively. A second group of 265 sires with $\geq 300$ daughters had on average $10,344,2,310$, and 889 daughters in $\mathrm{NA}, \mathrm{NE}$, and SE, respectively.

For the $\geq 100$ ( $\geq 300$ ) daughters groups using the standard model, the rank correlations of EBV between national and regional genetic evaluations were 0.87 (0.89) in SE and 0.96 (0.97) in NE (Table 4). This is similar to correlations of 0.88 and 0.97 obtained by Norman et al. (2005). Correlations increased with the number of daughters per sire, because they are dependent on sires' accuracies.

The rank correlations between the evaluations in NE and SE most likely overestimate the real correlations among cold and hot climate regions, which is mainly due to these factors: a) heat stress occurs only for a fraction of the year, b) heat stress is partially masked by cooling devices, and c) breeding of many cows in SE is timed to avoid having cows reach the peak of lactation in a period of severe heat stress. 


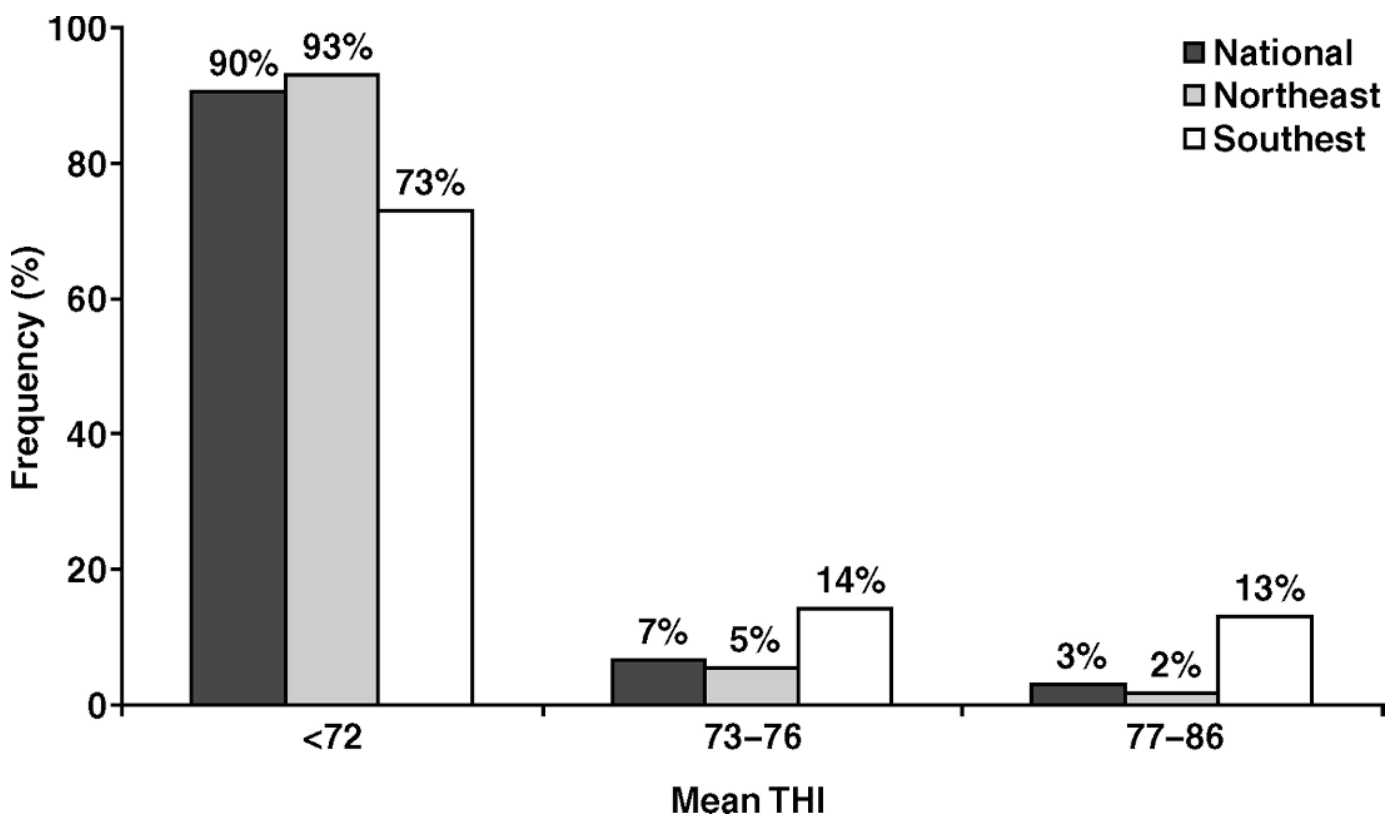

Figure 3. Frequency of test-day records with no heat stress [mean temperature-humidity index $($ THI $)<72$ ], moderate heat stress $(73 \leq$ mean THI $\leq 76$ ), and severe heat stress (mean THI $>76$ ) in National, Northeast, and Southeast data sets.

A sufficient number of records under heat stress would be required to achieve high reliability of sire evaluations. Unfortunately, regions with high levels of heat stress contribute a relatively small number of records to the national data set of US Holstein cattle. Lower correlations would be expected with data from regions where heat stress is present year round and where cooling devices are less common; for example, in parts of Brazil. When the heat-stress effect was added (the expanded model), the rank correlations increased by 0.005 in the $\geq 100$ daughter group and by 0.009 in the $\geq 300$ daughter group. The change was in the expected direction but small. Several explanations are possible: 1) presence of $\mathrm{G} \times \mathrm{E}$ due to reasons other than heat stress; 2) an oversimplified model; 3) inadequate weather records (climatic conditions on farms that use cooling devices are different from climatic conditions at the weather station); or 4) inadequate production data (at most, 6 TD with heat stress per cow). Freitas et al. (2006b) found that the response to heat stress based on TD records was about one-third of that obtained with daily records. This is because the accumulated effect of heat stress between the test-days cannot be considered and because only a few observations per year can be used to model variation in cooling over time. Also, the expanded model, as used in this study, captures instantaneous but not long-term response to heat stress.

Moreover, this model assumed the same THI definition, the same THI threshold, and the same response to heat stress per degree of THI for every herd in every region and over time. Assuming heterogeneous responses and thresholds would be more realistic. Bohmanova (2006) found that different THI definitions were preferable in Arizona and in Georgia. The definition in Georgia had a greater weight on humidity, which is the limiting factor of evaporative cooling in humid climates. The definition in Arizona had more weight on actual temperature because evaporative cooling is not limited by humidity in dry climates. Freitas et al. (2006b) found that the response to heat stress differed by herd size in regions subjected to limited heat stress. Larger herds,

Table 3. Average number of daughters per sire for 636 sires with $\geq 100$ daughters and for 265 sires with $\geq 300$ daughters in National, Northeast, and Southeast data sets

\begin{tabular}{|c|c|c|c|c|c|c|c|}
\hline & \multirow{2}{*}{$\begin{array}{c}\text { Sires } \\
(\mathrm{n})\end{array}$} & \multicolumn{3}{|c|}{ Mean number of daughters } & \multicolumn{3}{|c|}{ Median number of daughters } \\
\hline & & National & Northeast & Southeast & National & Northeast & Southeast \\
\hline$\geq 100$ daughte & 636 & 6,171 & 1,413 & 487 & 4,117 & 662 & 276 \\
\hline$\geq 300$ daughters & 265 & 10,344 & 2,310 & 889 & 8,579 & 1,499 & 579 \\
\hline
\end{tabular}


Table 4. Spearman correlations of sire EBV for heat tolerance additive effect $\left(\operatorname{Corr}_{\mathrm{a} 1 \_\mathrm{E}}\right)$, regular additive effect $\left(\operatorname{Corr}_{\mathrm{a} 0 \mathrm{E}}\right)$ using the expanded model, and regular additive effect $\left(\mathrm{Corr}_{\mathrm{a} \_\mathrm{S}}\right)$ using the standard model between Southeast (SE), Northeast (NE), and National (NA) data sets

\begin{tabular}{|c|c|c|c|c|c|c|c|c|c|}
\hline \multirow[b]{2}{*}{ Sires } & \multicolumn{3}{|c|}{$\operatorname{Corr}_{\mathrm{a} 1 \_\mathrm{E}}$} & \multicolumn{3}{|c|}{$\operatorname{Corr}_{\mathrm{a} 0 \_\mathrm{E}}$} & \multicolumn{3}{|c|}{$\operatorname{Corr}_{\mathrm{a} \_\mathrm{S}}$} \\
\hline & $\mathrm{SE} \times \mathrm{NE}$ & $\mathrm{SE} \times \mathrm{NA}$ & $\mathrm{NE} \times \mathrm{NA}$ & $\mathrm{SE} \times \mathrm{NE}$ & $\mathrm{SE} \times \mathrm{NA}$ & $\mathrm{NE} \times \mathrm{NA}$ & $\mathrm{SE} \times \mathrm{NE}$ & $\mathrm{SE} \times \mathrm{NA}$ & $\mathrm{NE} \times \mathrm{NA}$ \\
\hline$\geq 100^{1}$ & 0.575 & 0.789 & 0.774 & 0.845 & 0.873 & 0.962 & 0.840 & 0.871 & 0.961 \\
\hline$\geq 300^{2}$ & 0.715 & 0.880 & 0.847 & 0.874 & 0.896 & 0.970 & 0.864 & 0.891 & 0.970 \\
\hline
\end{tabular}

${ }^{1}$ Sires with $\geq 100$ daughters in both NE and SE data sets.

${ }^{2}$ Sires with $\geq 300$ daughters in both NE and SE data sets.

which were more likely to afford high-efficiency cooling devices, showed effects of heat stress only at much higher THI. In general, it could be desirable to account for differences in thresholds and rate of decline. Freitas et al. (2006a) found that using a lower-than-optimal threshold reduced $\mathrm{R}^{2}$ much less than using a threshold that was too high. Therefore, modeling variable thresholds per herd may have limited benefits (Freitas et al., 2006a). In addition, J. P. Sanchez (Univ. Georgia, Athens; personal communication) demonstrated that computing costs were very high for estimation of different thresholds per herd-year-season or sire when using a hierarchical Bayesian model.

This study used a repeatability model, whereas a random regression model could be more accurate because it better reflects the actual covariance structure of additive and permanent effects. However, because a preliminary analysis with random regression had shown some unreasonably high variances at the edges of lactation, which could have led to biased evaluations (J. Bohmanova, unpublished data), the repeatability model was chosen as a simpler alternative. If the majority of cows have the same number of test-days, the repeatability model could be almost as accurate as the random regression model because inaccuracies at various TD would partly cancel out.

One of the assumptions of the model used in this study is that the correlation between the regular and heat-tolerance EBV are constant throughout the lactation. In fact, one can expect that correlations are functions of DIM, and in particular, the most negative correlations are around the peak of lactation.

The correlations between the NE and SE data sets for the heat-stress EBV increased from 0.58 to 0.72 as the number of daughters per sire increased from 100 to 300 (Table 4). When sires with $\geq 700$ daughters were considered, the correlation reached 0.81 . Thus, the analyses in both regions identified similar heat-tolerant sires but only for sires with high accuracy. Because only a fraction of variability of heat stress is captured with the TD data, a large number of records is required to ensure reasonable accuracy.
Reliabilities of EBV for heat tolerance were low in this study. The accuracy is a function of the amount of heat stress in a particular region and the degree to which the effect of heat stress is captured through the infrequent (monthly) milk recording. More heat-stress information per cow was available in data collected in the SE than in the NE data set; however, the number of cows in the NE group is much larger. Assuming that daughters have, on average, 3 TD under heat stress with an average THI of $5^{\circ} \mathrm{C}$ above the threshold, the reliability of EBV for heat tolerance is equivalent to having about $1 / 20$ th the number of effective number of daughters for production. Thus, a given sire would need 1,000 daughters subjected to heat stress to achieve the same reliability for heat tolerance that could be obtained with 50 daughters for regular milk yield. In this study, the number of sires born after 1994 with at least 1,000 daughters (in the SE) was 74 .

The effect of heat stress as calculated using THI from public weather stations, and TD records accounted for a small part of the difference in EBV between the SE and NE data sets. Similar EBV for heat tolerance were calculated in different regions, but because a large number of daughters is required for sires to achieve high reliabilities of heat tolerance due to low heritability of this trait, the majority of sires had low reliabilities of EBV for heat tolerance.

\section{ACKNOWLEDGMENTS}

The authors thank J. B. Cole from Animal Improvement Programs Laboratory, USDA (Beltsville, MD) for providing the weather data. This study was supported by 58-1265-3-161 grant from AIPL/USDA.

\section{REFERENCES}

Bohmanova, J. 2006. Studies on genetics of heat stress in US Holsteins. PhD Diss. University of Georgia, Athens.

Bohmanova, J., I. Misztal, S. Tsuruta, H. D. Norman, and T. J. Lawlor. 2005. National genetic evaluation of milk yield for heat tolerance of United States Holsteins. Interbull Bull. 33:160-162.

Carabaño, M. J., K. M. Wade, and L. D. Van Vleck. 1990. Genotype by environment interactions for milk and fat production across regions of the United States. J. Dairy Sci. 73:173-180. 
Freitas, M., I. Misztal, J. Bohmanova, and R. Torres. 2006a. Regional differences in heat stress in US Holsteins. Proc. 8th World Congr. Genet. Appl. Livest. Prod., Belo Horizonte, Brazil.

Freitas, M., I. Misztal, J. Bohmanova, and J. W. West. 2006b. Utility of on- and off-farm weather records for studies in genetics of heat tolerance. Livest. Sci. 105:223-228.

Norman, H. D., P. M. VanRaden, R. L. Powell, J. R. Wright, and W. R. Verboort. 2005. Effectiveness of national and regional sire evaluations in predicting future-daughter milk yield. J. Dairy Sci. 88:812-826.

NRC. 1971. A Guide to Environmental Research on Animals. Natl. Acad. Sci., Washington, DC.

Ravagnolo, O., and I. Misztal. 2000. Genetic component of heat stress in dairy cattle, parameter estimation. J. Dairy Sci. 83:2126-2130.

Ravagnolo, O., and I. Misztal. 2002. Effect of heat stress on nonreturn rate in Holstein cows: Genetic analyses. J. Dairy Sci. 85:30923100 .
Rekaya, R., K. A. Weigel, and D. Gianola. 2003. Bayesian estimation of parameters of a structural model for genetic covariances between milk yield in five regions of the United States. J. Dairy Sci. 86:1837-1844

Tsuruta, S., I. Misztal, and I. Stranden. 2001. Use of the preconditioned conjugate gradient algorithm as a generic solver for mixedmodel equations in animal breeding applications. J. Anim. Sci. 79:1166-1172.

Weigel, K. A., R. Rekaya, N. R. Zwald, and W. F. Fikse. 2001. International genetic evaluation of dairy sires using a multiple-trait model with individual animal performance records. J. Dairy Sci. 84:2789-2795.

Zwald, N. R., K. A. Weigel, W. F. Fikse, and R. Rekaya. 2003. Identification of factors that cause genotype by environment interaction between herds of Holstein cattle in seventeen countries. J. Dairy Sci. 86:1009-1018. 